JURNAL SEKRETARIS DAN ADMINISTRASI BISNIS

Journal homepage http tljurnal asmtbacid

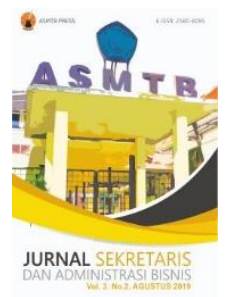

"Management of Incoming and Outgoing Mails using Aplikasi Manajemen Surat Korporat to Streamline The Administrative Process at PT PLN (Persero) UID West Java”

\title{
Pengelolaan Surat Masuk dan Surat Keluar dengan Menggunakan Aplikasi Manajemen Surat Korporat untuk Memperlancar Proses Administrasi di PT PLN (Persero) Unit Induk Distribusi (IUD) Jawa Barat
}

Carina Mutiara Putri ${ }^{1}$, Sofitianingsih ${ }^{2}$

${ }^{12}$ Akademi Sekretari dan Manajemen Taruna Bakti

1'carinamp1705@gmail.com; ${ }^{1}$ sofi.asmtb@yahoo.co.id

\begin{tabular}{l}
\hline Article info \\
\hline Article history: \\
Received $17^{\text {th }}$ June 2020 \\
Received in revised form $28^{\text {th }}$ May 2021 \\
Accepted $19^{\text {th }}$ August 2021 \\
\hline Keywords: \\
Administration process, \\
Manajemen Surat Korporat Application, \\
Management of Incoming and Outgoing \\
Mails
\end{tabular}

Abstract

The rapid development of technology in the digital age has a very big impact in changing the way people are working, from manual to computerized, that is include how to manage mails electronically. Aplikasi Manajemen Surat Korporat is an application that could expeditnd outgoing mails. The purpose of this research is to find out the process of managing incoming and outgoing mails using Aplikasi Manajemen Surat Korporat to fasten the administrative process at PT PLN (Persero) UID (Unit Induk Distributions) West Java. This study used qualitative research methods. Data collection techniques carried out by interviewing with branches of the Secretariat unit, observing, revieweing documents, and studying literature from books, journals, and documents relating to research discussions. The results showed that the management of incoming and outgoing mails using Aplikasi Manajemen Surat Korporat in PT PLN (Persero) UID West Java were good, the application were easy to work on, easy to learn, saving costs, fast, guaranteed security, could distributing information quickly so that every incoming and outgoing mails could be processed quickly, ultimately the service to the public can be improved. Some obstacles faced during the process were the unstable internet connection. 


\section{Pendahuluan}

Kebutuhan informasi muncul akibat kesenjangan pengetahuan yang ada dalam diri seseorang, sehingga untuk mengatasinya seseorang akan berusaha mencari informasi yang dibutuhkan agar segera terpenuhi, untuk memenuhinya juga mempunyai cara masing-masing. Menurut Belkin (Putri et al. 2019) bahwa "Kebutuhan dan perilaku pencarian informasi dapat dipengaruhi oleh bermacammacam sebab, antara lain latar belakang sosial, budaya, pendidikan, tujuan yang ada dalam diri manusia tersebut serta lingkungan sosialnya". Tidak setiap organisasi dengan mudah mendapatkan informasi yang benar-benar dengan sesuai kebutuhan dalam waktu yang cepat dan tepat sebagai alat untuk pengambilan sebuah keputusan. Sehingga dibutuhkan suatu sistem sebagai alat untuk mempercepat arus informasi, sebutan nama sistemnya tiap organisasi tentu akan berbeda tetapi memiliki tujuan yang sama yaitu untuk mempercepat pendistribusian baik surat masuk maupun surat keluar, hal ini sejalan dengan hasil penelitian dari (Rochmah, Hendriyani, and Ramadhanty 2020) menyatakan "The results of the study show that research and distribution of incoming mails using Dropbox conducted by BPJS Employment Cimahi in the digital era is currently facilitating work processes and internal communication between employees and encouraging new goals for companies that can be used quickly."

Melalui sistem inilah sebuah proses pekerjaan administrasi arus informasi akan lebih akurat, terencana, terprogram, serta memudahkan untuk pengawasan dan komunikasi akan terjadi secara 2 (dua) / two ways communication. Prosedur pengurusan surat dibedakan yaitu prosedur surat masuk dan surat keluar. Sedarmayanti (2014) menyatakan "Mengurus dan mengendalikan surat adalah kegiatan mengelola surat masuk dan surat keluar yang meliputi kegiatan menerima, mencatat, mengarahkan, mendistribusikan, memproses lebih lanjut, dan menyimpan surat sesuai dengan prosedur yang berlaku." Pengelolaan surat yang tidak efektif dapat menimbulkan kelambatan dan kegagalan dalam pencapaian tujuan organisasi.

Cara penyimpanan data / surat dengan cara disimpan dimana saja, tidak ada aturan yang jelas dan akurat akan terjadi penumpukan dimana-mana baik dalam satu ruangan maupun yang berbeda ruangan, akan rentan terjadi kerusakan yang dialami akibat lamanya usia surat dilemari penyimpanan serta kerumitan dalam pencarian surat, untuk mengatasi hal tersebut dibutuhkan suatu sistem informasi yang berbasis teknonogi digital. Hal ini sejalan dengan pendapat (Wahyu Fitriana Kurnia Sari 2018) hasil penelitiannya menyatakan "Prosedur pengolahan surat memiliki peran yang sangat penting bagi setiap perusahaan, terutama bagi perusahaan yang memiliki tingkat pekerjaan yang tinggi dan memiliki banyak surat yang harus dikelola, tidak mungkin menggunakan cara manual, pengolaan surat dalam jumlah banyak sangat memerlukan alat bantu untuk mengelola surat-surat 
tersebut, agar pengolaan surat dapat dikerjakan secara efektif dan efisien. Suryana ( 2012) menyatakan "Aplikasi pengelolaan dokumen yang dikembangkan dapat digunakan untuk mengatur dan mengelola surat-surat ataupun dokumen-dokumen penting agar dokumen tersebut mudah untuk dicari dan ditemukan kembali, bermanfaat dalam mengefektifkan dan mengefisienkan proses pencarian menjadi lebih cepat, lebih baik dan murah."

Sistem aplikasi surat elektronik menarik bagi institusi salah satunya ingin menjadikan instansi yang ramah lingkungan. Keuntungan dari arsip elektronik adalah sangatlah mudah untuk dipindahkan, dibagi ataupun digandakan, arsip elektronik jauh lebih mudah dan cepat diakses dalam proses pencarian dan penemuan kembali. Konsep paperless office menjadi isu penting yang diadopsi oleh berbagai organisasi bisnis maupun sosial saat ini sebagai respon atas terjadinya pemanasan bumi yang terjadi. Dari perspektif finansial, kemudahan-kemudahan tersebut tentunya membuat institusi mampu menghemat biaya. Hal ini sejalan dengan pendapat (Trizaka, Rusdianto, and Brata 2019) hasil penelitiannya menyatakan "Guna memudahkan penanganan surat di lingkungannya Fakultas Ilmu Komputer dibuatlah sebuah aplikasi bernama SIAS (Sistem Informasi Administrasi Surat) merupakan sistem layanan yang diharapkan dapat mengatasi masalah persuratan di Universitas Brawijaya.”. Menurut (Utari and Wibowo 2013) bahwa “Arsip elektronis (Electronic-File) adalah kumpulan data yang disimpan dalam bentuk data scan-an yang dipindahkan secara elektronik atau dilakukan digital copy menggunakan resolusi tinggi, kemudian disimpan dalam hard drive atau optical disk." Berdasarkan penelitian terdahulu di atas, peneliti tertarik untuk melakukan suatu penelitian dengan tujuan untuk mengetahui bagaimana prosedur surat menyurat berbasis elektronik di sebuah perusahaan sebagai bagian dari proses administrasi, dengan judul penelitian "Pengelolaan Surat Masuk dan Surat Keluar dengan Menggunakan Aplikasi Manajemen Surat Korporat untuk Memperlancar Proses Administrasi di PT PLN (Pesero)Unit Induk Distribusi (IUD) Jawa Barat.

\section{Metodologi Penelitian}

Teknik analisis data dalam penilitian ini menggunakan teknik kualitatif dengan studi literature yang komprehensif dengan pendekatan deskriptif yang dijadikan obyek penelitian adalah kantor pusat PT PLN (Persero) UID Jawa Barat, karena PT PLN (Persero) merupakan perusahaan BUMN yang besar, kegiatan surat menyuratnya sangat tinggi baik dalam melayani publik internal maupun publik eksternal. 


\section{Hasil dan Diskusi}

\section{Prosedur Surat Masuk Menggunakan Aplikasi Manajemen Surat Korporat di PT PLN (Persero) UID Jawa Barat}

Setiap surat masuk yang di terima oleh PT PLN (Persero) UID Jawa Barat dibagi menjadi 2 (dua) yaitu surat masuk internal dan surat masuk eksternal. Yang dimaksud surat masuk internal yaitu surat yang di kirim dari seluruh unit PT PLN (Persero) di Indonesia dan surat yang masuk langsung terkirim kepada penerima surat, sedangkan surat masuk eksternal yaitu surat masuk yang diterima oleh pihak ke-3 dan proses pengimputan data surat masuk tersebut dilakukan oleh pihak sekretariat, contohnya instansi pemerintah. Surat masuk yang dikirim oleh pihak eksternal harus melalui pihak sekretariat terlebih dahulu karena bentuk surat yang diterima berbentuk dokumen surat asli sehingga surat harus di ubah terlebih dahulu menjadi file digital. Sedangkan surat masuk antar PT PLN (Persero) surat akan di terima langsung oleh penerima surat melalui AMS Korporat. PT PLN (Persero) UID Jawa Barat memiliki sifat surat masuk yang dibedakan menjadi 2 (dua) ialah Rahasia dan Bukan Rahasia. Bersifat rahasia yaitu surat yang hanya boleh di baca oleh pihak yang dituju misalnya surat peringatan, perintah kerja. Surat bukan rahasia yaitu surat yang hanya boleh dibaca oleh bagian pengelola surat.

Seluruh anggota pegawai atau user diberikan wewenang untuk mengakses AMS Korporat dengan syarat melakukan pendaftaran terlebih dahulu sesuai dengan bidang masing-masing. Setelah karyawan mendapatkan id akses barulah karyawan dapat mengakses AMS Korporat di $p c$ masingmasing, namun hanya bagian sekretariat yang dapat mengoprasikan, menginput dan melihat semua surat masuk dari pihak eksternal PT PLN (Persero) UID Jawa Barat. Dalam proses pengaksesannya karyawan tetap dikontrol oleh perusahaan dengan diberikannya pelatihan pengoprasian AMS Korporat, diberikan pembekalan Standard Operating Procedure (SOP). Berikut adalah flowchart prosedur pengolaan proses surat masuk dari pihak internal dan pihak eksternal unit PT PLN(Persero) UID Jawa Barat dalam menggunakan Aplikasi Manajemen Surat Korporat. Mengenai flowchart prosedur surat masuk dari pihak eksternal PT PLN(Persero) UID Jawa Barat dapat dilihat pada gambar 1.1 dibawah ini: 


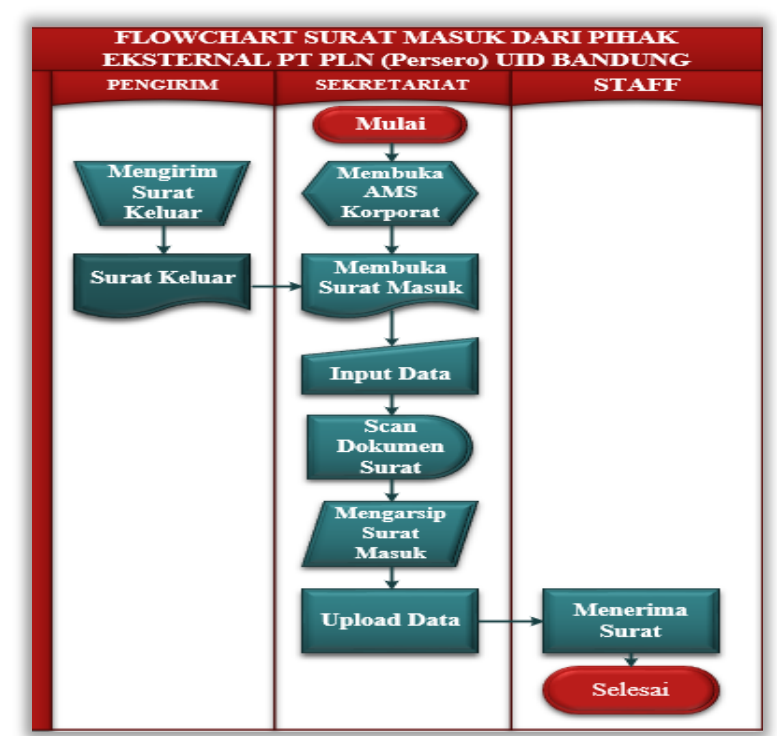

Gambar 1.1 Flowchart Surat Masuk dari Pihak Eksternal PT PLN (Persero) UID Jawa Barat

Sumber: PT PLN (Persero) UID Jawa Barat

Keterangan Flowchart:

Pertama untuk membuat surat masuk dari pihak eksternal PT PLN (Persero) UID Jawa Barat adalah sekretariat membuka aplikasi AMS Korporat dengan memasukkan username dan password yang sudah terdaftar dan memastikan apakah surat masuk tersebut benar ditujukan untuk PT PLN (Persero) UID Jawa Barat agar surat dapat bisa di inputkan ke dalam AMS Korporat. Proses pengimputan data surat dimulai dari 1) Tahun Agenda; 2) Tanggal Terima Surat; 3 ) Nomor Surat; 4) Tanggal Surat; 5) Dari (Pengirim Surat); 6) Kepada (Ditujukan untuk siapa); 7) Tebusan; 8) Hal; 9) Lampiran apakah surat tersebut berbentuk Buku, lembar, Set, Rangkap; 10) Kode Klasifikasi; 11) Sifat (Pengamanan) apakah bersifat biasa, terbatas, rahasia dan sangat rahasia; 12) Sifat (Penyampaian) apakah bersifat biasa, segera, sangat segera dan 13) Keterangan. Setelah menginput data, selanjutnya mengubah bentuk dokumen hardcopy menjadi file digital dengan cara melakukan proses scan pada surat tersebut dan disimpan kedalam folder scanner dalam bentuk .pdf lalu mengcopy surat tersebut kedalam AMS Korporat dan surat dapat langsung di upload ke dalam AMS Korporat untuk segera di disposisikan kepada penerima surat secara real time. Apabila surat tersebut sudah terkirim user akan mengecek dan memastikan apakah surat masuk tersebut sudah terkirim atau tidak, tindakan double check selalu diterapkan di PT PLN (Persero) UID Jawa Barat agar tidak ada kesalahan dalam proses pengiriman surat masuk. Cara agar mempermudahkan dalam proses pencarian surat masuk yang sudah terkirim, yaitu dengan cara mencari dari tanggal surat atau kata kunci dari surat tersebut yang dapat memudahkan pencarian surat, sehingga surat yang dicari dapat mudah ditemukan.

Penerima surat akan menerima surat secara elektronis pada menu surat masuk yang terdapat pada penerima surat dengan begitu proses administrasi akan berjalan dengan terlaksana dengan cepat. 
Sebelum surat di upload user akan mengarsipkan surat tersebut baik hardcopy maupun softcopy. Surat hardcopy akan digandakan dan disimpan untuk kebutuhan arsip di dalam ordner dan disimpan ke dalam filling cabinet sementara selama setahun dengan sistem subjectical yang terdapat di ruangan sekretariat setelah setahun dokumen surat tersebut dipindahan ke bagian ruangan pengersipan PT PLN (Persero) UID Jawa Barat, sedangkan untuk softcopy data yang sudah di scan akan disimpan di dalam AMS Korporat dengan keamanan yang sangat aman.

\section{Surat Masuk Antar Unit PT PLN (Persero) UID Jawa Barat}

Proses surat masuk antar unit PT PLN (Persero) UID Jawa Barat semua proses surat masuk akan langsung terkirim kepada penerima surat sehingga proses administrasi akan terlaksana dan terselesaikan dengan cepat.

Berikut adalah flowchart surat masuk antar unit PT PLN (Persero) UID Jawa Barat, Mengenai flowchart prosedur surat masuk antar PT PLN (Persero) UID Jawa Barat dapat dilihat pada gambar 1.2 di bawah ini:

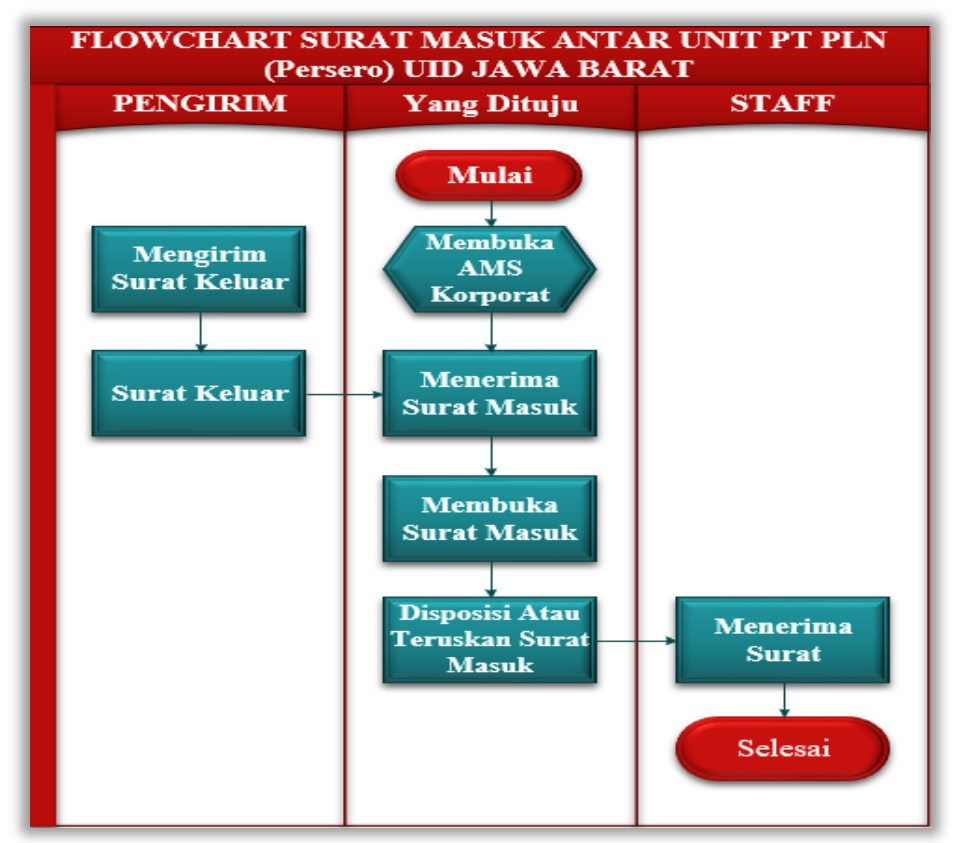

Gambar 1.2 Flowchart Surat Masuk Antar Unit PT PLN (Persero) UID Jawa Barat

Sumber : PT PLN (Persero) UID Jawa Barat

Keterangan Flowchart:

Hal pertama yang dilakukan dalam proses surat masuk antar unit PT PLN (Persero) UID Jawa Barat adalah user melakukan login dengan memasukan username dan password ke dalam aplikasi AMS Korporat agar dapat membuka menu halaman "Surat Masuk" pada aplikasi AMS Korporat dan langkah selanjutnya adalah memastikan apakah surat masuk tersebut ditujukan dengan benar kepada penerima surat. Apabila surat tersebut ditujukan sudah benar proses disposisi surat dapat dilakukan kepada pihak yang dituju selanjutnya surat dapat langsung untuk di cetak. 
Proses penambahan disposisi surat apabila surat tersebut akan di tindak lanjuti, user harus menginput beberapa ketentuan yang di dalamnya terdapat 11 (sebelas) pilihan mengenai tujuan dari disposisi surat tersebut apakah untuk:1)Untuk Diketahui;2)Diperhatikan;3)Untuk Dipelajari;4)Disiapkan Jawaban;5)Jawab Langsung;6)ACC Untuk Ditindak Lanjuti;7)Ambil Langkah Seperlunya;8)Dibicarakan;9)Dilaporkan;10)segera Diselesaikan dan 11)Copy Ditujukan kepada siapa disposisi tersebut, dan mengisi keterangan apabila ada info tambahan yang akan disampaikan dan terakhir memilih tipe disposisi apakah terbuka atau tertutup. Terbuka adalah riwayat disposisi dapat dilihat dan dibaca oleh semua penerima disposisi sedangakan tertutup hanya bisa dilihat oleh penerima dan pengirim disposisi. Apabila proses disposisi sudah selesai surat tidak akan bisa lagi di disposisikan melainkan hanya bisa "Diteruskan".

\section{Prosedur Surat Keluar Menggunakan Aplikasi Manajemen Surat Korporat di PT PLN (Persero) UID Jawa Barat}

Surat keluar internal PT PLN(Persero) UID Jawa Barat yang akan dikirim melalui AMS Korporat akan otomatis tersimpan di AMS Korporat setelah pengiriman berhasil, sedangkan untuk surat keluar eksternal sebelum surat dikirim surat harus dicetak terlebih dahulu oleh sekretaris fungsi atau sekretaris dari Manager unit tersebut untuk mendapatkan tanda tangan basah dari pengirim surat agar selanjutkan surat tersebut dapat di scan untuk di upload dan disimpan di dalam AMS Korporat. Proses pembuatan surat keluar harus dilakukan dengan sedetail mungkin agar tidak ada proses pengulangan surat kembali.

Berikut adalah flowchart prosedur pengelolaan surat masuk antar unit PT PLN (Persero) UID Jawa Barat, Mengenai flowchart prosedur surat keluar dapat dilihat pada gambar 1.3 dibawah ini: 


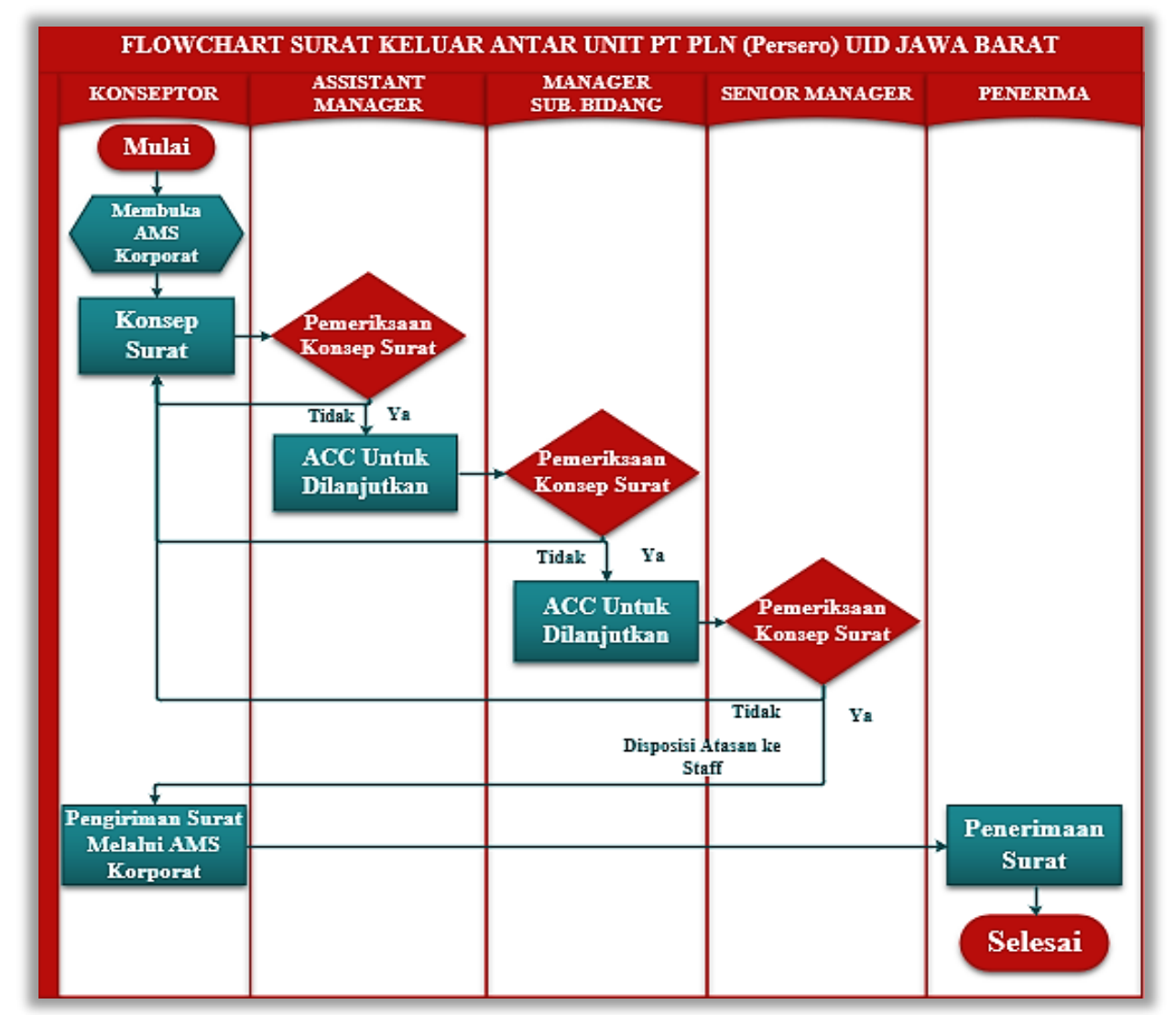

Gambar 1.3 Flowchart Surat Keluar Antar Unit PT PLN (Persero) UID Jawa Barat

Sumber : PT PLN (Persero) UID Jawa Barat

Keterangan Flowchart:

Proses surat keluar antar unit PT PLN (Persero) UID Jawa Barat merupakan fungsi yang bertujuan untuk membalas surat masuk yang di terima dari seluruh unit PT PLN (Persero). Hal pertama yang dilakukan adalah konseptor menginput draft surat keluar dengan mengisi 4 (empat) tahap yaitu: 1)Kepala Surat;2)Data Pengirim;3)Penerima Surat;4)Pemeriksa Surat di dalam Aplikasi Manajemen Surat Korporat.

Terdapat 4 tahapan dalam pengiriman surat yang pertama konseptor lakukan adalah menginput data surat di bagian "Kepala Surat". Dalam kepala surat konseptor menginput: 1)Hal;2)Lampiran, apakah surat tersebut berbentuk Buku, lembar, Set, Rangkap;4)Pokok Kegiatan surat;5)Kode Klasifikasi;6)Sifat (Pengamanan) apakah Biasa, Terbatas, Rahasia dan Sangat Rahasia;7)Sifat (Penyampaian) apakah Biasa, Segera, Sangat Segera setelah menginput data tersebut konseptor dapat membuat isi surat surat tersebut. Tahap yang ke-2 yaitu "Pengirim" adalah konseptor mengisi data dari pengirim surat dengan mencantumkan nama dari "Jabatan" pengirim surat tersebut selanjutnya untuk kolom Nama Pejabat, NIP, Nama Unit, Bussiness Organisasi akan terisi secara otomatis. 
Tahap ke-3 yaitu "Penerima" adalah konseptor menginput data dari pengirim surat mulai dari nama pejabat atau pegawai dan memilih bentuk tanda tangan yang diterima jika penerima surat kepada pihak internal maka bentuk tanda tangan yang diterima berbentuk " $Q R$ Code" jika surat tersebut ditujukan kepada pihak eksternal maka tanda tangan yang diterima berbentuk tanda tangan basah. Tahap ke-4 yaitu "Pemeriksa" sebelum surat diperiksa dan dikirim oleh konseptor, juga harus memasukan nama-nama dari pemeriksa surat dari masing-masing pejabat tiap unitnya yang ditunjuk sebagai pemeriksa, dimulai dari Assistand Manager, Manager Sub Bidang dan Senior Manage selanjutnya surat dapat dikirim agar mendapatkan persetujuan. Apabila surat yang diperiksa tidak disetujui atau ditolak maka surat tersebut akan di kembalikan lagi kepada konseptor, jika surat tersebut diterima atau disetujui maka secara otomatis $Q R$ Code akan muncul. Sehingga proses approval tersebut berlanjut hingga proses pengiriman surat yang dilakukan oleh konseptor. Proses approval bertujuan agar kualitas dari surat yang akan dikirim menghasilkan surat yang berkualitas sehingga diperlukan proses pemeriksaan surat.

\section{Surat Keluar untuk Pihak Eksternal PT PLN (Persero) UID Jawa Barat}

Proses surat keluar untuk pihak eksternal PT PLN (Persero) UID Jawa Barat merupakan fungsi yang bertujuan untuk membalas surat masuk yang di terima dari pihak eksternal. Setelah proses pemeriksaan surat, surat akan di cetak untuk mendapatkan tanda tangan basah dari pengirim surat dan surat yang sudah mendapatkan tanda tangan tersebut di scan dan di upload kedalam AMS Korporat untuk di arsipkan dan surat hardcopy tersebut dapat langsung dikirim, karena PT PLN (Persero) UID Jawa Barat berkerja sama dengan POS Indonesia maka proses pengiriman surat akan di kirim melalui POS.

Berikut adalah flowchart untuk surat keluar eksternal PT PLN (Persero) UID Jawa Barat, Mengenai flowcart prosedur surat keluar dapat dilihat pada gambar 1.4 dibawah ini: 


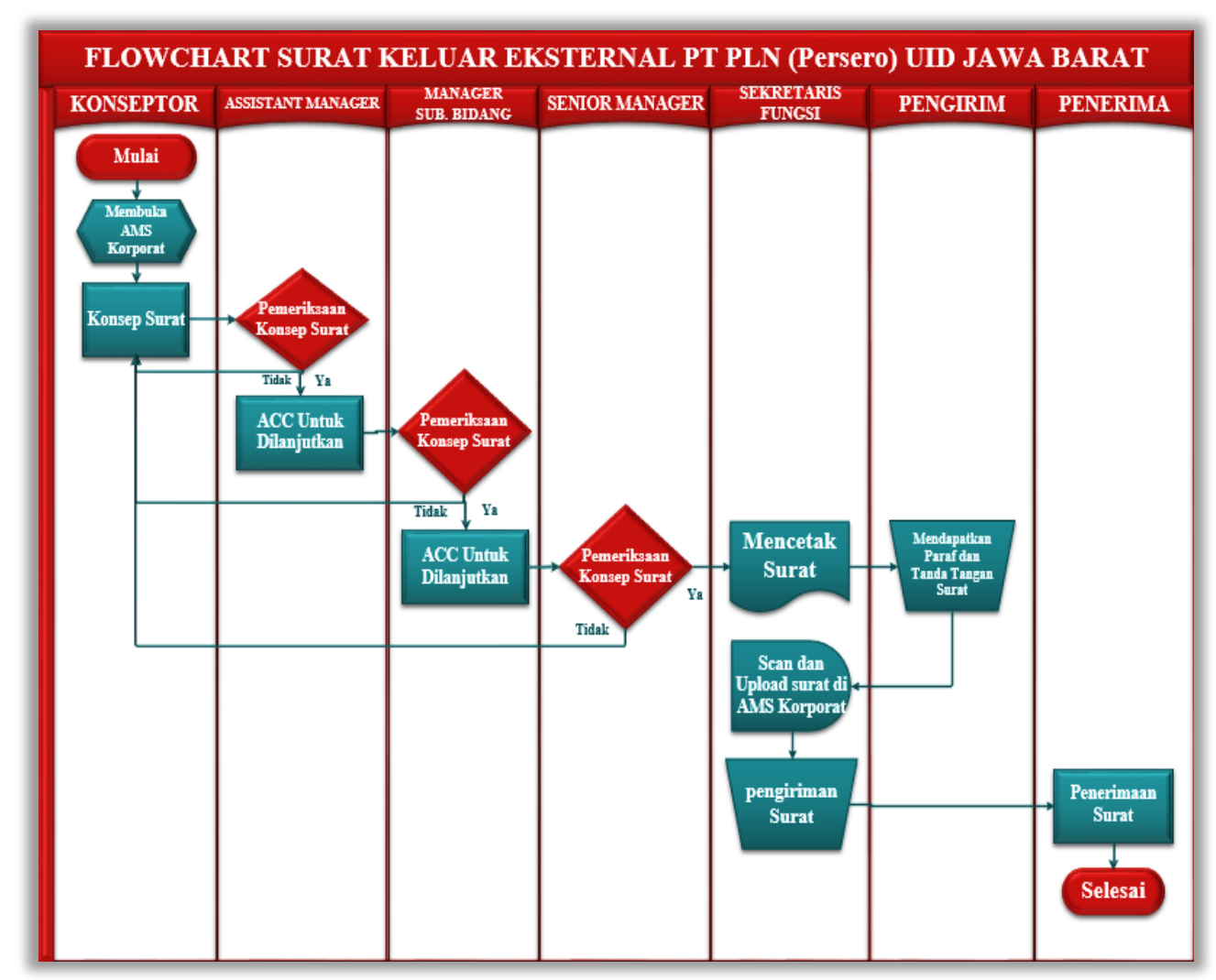

Gambar 1.4 Flowchart Surat Keluar Eksternal PT PLN (Persero) UID Jawa Barat

Sumber : PT PLN (Persero) UID Jawa Barat

Keterangan Flowchart:

Pada dasarnya proses pembuatan surat untuk pihak eksternal sama saja dengan proses surat masuk untuk pihak internal PT PLN (Persero) UID Jawa Barat namun terdapat perbedaan dalam bentuk tanda tangan dan bentuk surat yang di terima. Setelah proses pemeriksaan surat yang sudah di setujui, dengan otomatis sekretaris akan mendapatkan notifikasi surat yang harus segera di cetak. Surat yang sudah dicetak lalu diserahkan kepada pengirim surat untuk mendapatkan tanda tangan basah dari pengirim surat. Surat yang sudah di tanda tangan basah dan di cap oleh pengirim surat, surat harus di upload ke dalam AMS Korporat dengan cara melakukan proses scan pada surat tersebut dan dapat di upload ke dalam AMS Korporat yang bertujuan untuk mendapatkan soft file dokumen yang akan di arisipkan untuk pihak internal PT PLN (Persero) UID Jawa Barat. Surat yang berbentuk hardcopy dapat langsung di distribusikan ke pihak eksternal penerima surat melalui jasa pengriman surat POS Indonesia. 


\section{Pengaruh penggunaan surat masuk dan keluar dengan menggunakan Aplikasi Manajemen} Surat Korporat terhadap kelancaran proses administrasi di PT PLN (Persero) UID Jawa Barat.

Hasil wawancara penulis dengan Assistant Manager beserta staff dari Unit Sekretariat Departemen Genneral Affair PT PLN(Persero) UID Jawa Barat (daftar pertanyaan terlampir) menyatakan bahwa lajunya perkembangan zaman hampir semua pekerjaan proses administrasi dalam mengelola dokumen, baik surat masuk dan surat keluar beralih menggunakan media elektronik, tentunya hal tersebut sangat tidak mudah untuk mengubah budaya kerja yang sebelumnya sangat menitik beratkan pengelolaan dokumen berbasis fisik menjadi berbeda sama sekali tentunya tidak mudah. Hal ini sejalan dengan hasil penelitian (Putranto n.d.) menyatakan dalam jurnalnya bahwa "Pengelolaan arsip elektronik bukanlah sekedar mengaplikasikan perangkat lunak dalam sistem, namun merupakan perubahan budaya."

Pengaruh penggunaan Aplikasi Manajemen Surat Koporat ini telah berpengaruh terhadap proses administrasi yaitu mudah, cepat, kerahasiaan dapat dijaga, keamanan lebih terjamin, dapat mengurangi pengeluaran biaya, meningkatkan efisiensi sekaligus mengurangi penggunaan pengeluaran kertas. Walaupun penggunaan kertas kerap masih di gunakan tapi jumlah kertas yang di keluarkan tidak sebanyak proses surat menyurat secara manual. Hingga saat ini, arsip berbasis kertas (hardcopy) dan elektronik masih digunakan secara berdampingan. Salah satu perubahan dengan berlaihnya menggunakan AMS Korporat yaitu dalam bentuk tanda tangan elektronik, sehingga dapat memperlancar proses administrasi dapat membantu pekerjaan karyawan dengan cepat akhirnya pelayanan informasi dapat ditingkatkan.

\section{Diskusi}

\section{Aplikasi Manajemen Surat Korporat di PT PLN (Persero) UID Jawa Barat}

Menurut Liga Sabina.L dalam hasil ilmiahnya (Luntungan 2013) bahwa "Surat elektronik atau Electronic Mail yang sering disingkat dengan E-mail adalah salah satu fasilitas di internet yang begitu menyusun dan merupakan fasilitas yang paling awal dikembangkan di internet dengan menyusun, mengirimkan, membaca, membalas, dan mengelola pesan secara elektronis dengan mudah, cepat, tepat, dan aman." Surat sangat penting dalam membantu dan memperlancar tercapainya tujuan suatu organisasi. Karena sifatnya yang demikian, maka surat-surat harus disusun secara singkat dan padat tetapi jelas dan tegas. Sedangkan surat keluar menurut Sedianingsih (Sari 2018) "Menyatakan bahwa surat keluar adalah menerima pendiktean atau konsep, Mencatat pada buku agenda atau kartu kendali, mengetik konsep surat, meminta tanda tangan kepada pimpinan, 
mengecek surat yang akan dikirim, mendistribusikan surat. Surat siap dikirim baik melaui pos, jasa kurir, atau jika dalam kota biasanya dapat menggunakan office boy kantor." (dalam jurnal [Rita Permata Sari] (Sari 2018).

Aplikasi Manajemen Surat Korporat merupakan suatu aplikasi komputer yang berfungsi sebagai sarana untuk pengelolaan administrasi kesekretariatan, kelancaran penerimaan surat, pendistribusian surat, pengeluaran surat, pencarian surat baik surat masuk, surat keluar, produk hukum, surat bentuk khusus maupun nota dinas. Aplikasi ini dipakai untuk menyimpan data surat menyurat dalam bentuk softcopy dan memberikan kemudahan bagi user dalam melakukan pengarsipan maupun pencarian dokumen, diharapkan dapat mempermudah dalam melakukan pengelolaan administrasi kesekretariatan secara elektronik yang di dalamnya terdiri dari surat masuk, surat keluar, nota dinas, surat rahasia dan lain sebagainya. Berdasarkan pengamatan penulis, menumenu diletakkan dengan rapi, serta menggunakan Bahasa Indonesia yang baik. Desain tampilan AMS Korporat simple, warna yang digunakan adalah kombinasi warna putih dan hijau toska yang tidak mencolok di mata. Oleh sebab itu pengguna merasa nyaman untuk menggunakan Aplikasi Manajemen Surat Korporat.

Berdasarkan hasil wawancara penulis dengan para pegawai yang menggunakan aplikasi ini (daftar pertanyaan terlampir) menyatakan bahwa Aplikasi Manajemen Surat Korporat untuk yang surat yang dikirim akan diterima secara cepat dan real time, menghemat biaya, memiliki cara penyimpanan dokumen dalam bentuk soft file dalam suatu komputer atau server sehingga tidak memerlukan tempat yang luas, dapat dilakukan dimana saja dan kapan saja. Hal ini didukung oleh Lawalata (Sari 2018) menyatakan bahwa "Kelebihan prosedur pengelolaan elektronik adalah: 1) Proses pengolahan cepat sehingga mempersingkat waktu pekerjaan; 2) Tingkat akurasi informasi yang dihasilkan cukup tinggi; 3) Informasi yang dihasilkan akurat, sesuai dengan tujuan pengolahan data; 4) Kemudahan berinteraksi dengan penggunanya dalam menjalankan aplikasi-aplikasi yang berbasis computer" juga ddidukung oleh Dyah.R.U, Arief, W, (Utari and Wibowo 2013) menyatakan bahwa "Pengelolaan surat berbasis elektronik jauh lebih efisien di bandingkan dengan surat secara manual dikarenakan dengan adanya Aplikasi Manajemen Surat Korporat dapat menghemat pengeluaran biaya, proses pengiriman surat yang cepat serta tidak banyak memerlukan banyak ruang."

AMS korporat menawarkan kemudahan dalam bekerja bagi karyawan di PT PLN (Persero) UID Jawa Barat. Kelebihan dari AMS Korporat yaitu 1) Mengurangi pengeluaran biaya dalam proses pengiriman surat serta dalam pengeluaran operasional seperti penghematan dalam jumlah kertas yang digunakan dengan menerapkan konsep paperless; 2) Proses pengiriman surat dapat dikirim ke seluruh unit PT PLN (Persero) di seluruh Indonesia dalam waktu yang bersamaan; 3) Proses pengiriman surat 
diproses dengan cepat, sudah tidak menggunakan jasa pos sepenuhnya seperti sebelumnya, akan tetapi penggunanaan pos masih tetap digunakan namun hanya untuk mitra eksternal; 4) Dapat dengan mudah dalam mengakses data arsip yang telah tersimpan yang disebabkan oleh penyimpanan arsip yang baik dan teratur; 5) Kerusakan dokumen arsip dapat diminimalisir.; 6) Dapat memudahkan mobilitas surat terkait dengan disposisi surat, karena setiap pegawai PT PLN (Persero) UID Jawa Barat memiliki akun dari AMS Korporat oleh karena itu proses disposisi surat dapat langsung diterima begitu surat ter-upload; 6) Dapat dengan mudah untuk di akses dimana saja dan kapan saja; 7) Pembuatan surat rahasia dapat di laksanakan dengan AMS Korporat, dimana AMS yang lama masih di kerjakan secara manual; 8) Proses menemuan kembali surat hanya bisa dilihat oleh konseptor dan penerima surat, dengan begitu tidak semua karyawan dapat dengan mudah untuk membuka dokumen surat tersebut. Hal ini sejalan dengan hasil penelitian Mira V (Veranita and Ganesha 2018) dalam jurnal menyatakan bahwa "Keuntungan dalam penerapan arsip elektronik adalah Kegiatan pengindeksan, pencarian dan penemuan kembali arsip dapat dilakukan dengan cepat, fleksibel dan mudah dimodifikasi berdasarkan prosedur yang telah dikembangkan.” Kendala yang terjadi gangguan pada jaringan internet yang mengakibatkan proses surat menyurat terganggu.

\section{Simpulan}

Pengelolaan surat masuk dan surat keluar dengan menggunakan aplikasi manajemen surat korporat di PT PLN (Persero) UID Jawa Barat sudah baik, prosedurnya sederhana, sistemnya mudah di kerjakan, mudah di pelajari, menghemat biaya, lebih cepat pengerjaannya, terjamin keamanannya, dapat mendistribusikan informasi dengan cepat dalam waktu yang bersamaan keberbagai bagian, sehingga setiap surat yang masuk maupun keluar dapat dengan segera diproses atau difollow dengan cepat akhirnya pelayanan kepada publik internal dan publik dapat meningkat. Terdapat hambatan yang sifatnya umum adalah terjadinya ganguan pada jaringan internet yang dapat diatasi ketika jaringan membaik kembali.

\section{Saran}

Dalam rangka meningkatkan pelayanan kepada masyarakat, alangkah baiknya jaringan internetnya di pelihara dengan baik, sehingga kualitas pekerjaan dapat meningkat.

\section{Arah Penelitian Di Masa Depan}

Untuk penelitian selanjutnya di sarankan untuk meneliti mengenai bagaimana sistem penyimpanan arsip secara elektronik dengan judul "Analisis Penggunaan E-Filling Untuk Menjaga Kerahasian Dokumen Di PT PLN (Persero) UID Jawa Barat.” 


\section{Referensi}

Luntungan, Liga Sabina. 2013. "Keabsahan Alat Bukti Short Message Service (SMS) Dan Surat Elektronik Dalam Kasus Pidana.” II(3): 173-84.

Putranto, Widiatmoko Adi. "Pengelolaan Arsip Elektronik Dalam Proses Administrasi : Electronic Records Management in Administrative Process :" :77-90.

Putri, Agustina Eka, Ute Lies Siti Khadijah, Evi Novianti, and Awaludin Nugraha. 2019. "Perilaku Pencarian Informasi Wisatawan Terhadap Pemenuhan Behavior of Tourist Information Search to Fulfill Information about Pangandaran as Tourism Destinastion." 1(1): 7-11.

Rochmah, Tengku Sitti, Chandra Hendriyani, and Shafira Ramadhanty. 2020. "Penanganan Surat Masuk Dengan Aplikasi Dropbox Untuk Efektifivitas Komunikasi Internal Di Era Digital." IV(1): 21-31.

Sari, Rita Permata. 2018. "Implementasi Aplikasi Manajemen Surat (Ams) Dalam Prosedur Pengelolaan Surat Masuk Dan Surat Keluar Di PT PLN (PERSERO) Wilayah Sumatera Barat." 1: 260-66.

Sedarmayanti. 2014. "Tugas Dan Pengembangan Sekretaris Profesional Untuk Meraih Keberhasilan (Edisi Revisi)." In mandar maju.

Suryana, Taryana. 2012. "Pengelolaan Dokumen Sebagai Sarana Komunikasi Internal Unikom.” Jurnal Komputer Dan Informatika (KOMPUTA) 1(1): 1-9.

Trizaka, Habib, Denny Sagita Rusdianto, and Adam Hendra Brata. 2019. "Pengembangan Sistem Aplikasi Persuratan Elektronik Berbasis Web Di Fakultas Ilmu Komputer ( FILKOM ) Universitas Brawijaya." 3(5): 5115-21.

Utari, Dyah Retno, and Arief Wibowo. 2013. "Penanganan Arsip Secara Elektronik: Inovasi Bidang Administrasi Perkantoran Dalam Usaha Pelestarian Lingkungan." Prosiding ISBN (November 2013): 602-978.

Veranita, Mira, and Politeknik Piksi Ganesha. 2018. "Implementasi Electronic Filing ( E-FILING) Dalam Mendukung Pelayanan Administrasi Implementasi Electronic Filing ( E-FILING )." (October).

Wahyu Fitriana Kurnia Sari. 2018. "Prosedur Pengelolaan Surat Masuk Dan Surat Keluar Dengan Aplikasi Manajemen Surat (Ams) Pada PT. PLN ( Persero) APJ Surakarta.” Journal of Materials Processing Technology 1(1): 1-8. http://dx.doi.org/10.1016/j.cirp.2016.06.001\%0Ahttp://dx.doi.org/10.1016/j.powtec.2016.12.05 5\%0Ahttps://doi.org/10.1016/j.ijfatigue.2019.02.006\%0Ahttps://doi.org/10.1016/j.matlet.2019. 04.024\%0Ahttps://doi.org/10.1016/j.matlet.2019.127252\%0Ahttp://dx.doi.o.ss 